\title{
Qualidade do milho para nutrição animal comercializado a varejo e métodos para determinação da umidade
}

\author{
Daviane Martinele Costa ${ }^{1}$ \\ Luiz Carlos Machado² \\ Flávio Bittencourt ${ }^{3}$ \\ Larisse Cristina Pereira 4
}

\section{Resumo}

O Brasil já alcançou a marca histórica de 61 milhões de toneladas de ração produzidas anualmente e cerca de $65 \%$ é composta por milho, cuja qualidade nutricional sofre influência de diversos fatores. Parte do milho comercializado não passa por controle de qualidade e é aceita sem quaisquer restrições. $\mathrm{O}$ objetivo deste trabalho foi avaliar a qualidade do milho comercializado a varejo e determinar sua umidade por diferentes métodos, uma vez que vários métodos podem ser utilizados sem a certeza de sua confiabilidade. Amostras de milho foram coletadas em quatro casas agropecuárias de Bambuí-MG durante 12 meses. Foram avaliadas a proteína bruta (PB), a umidade em três diferentes metodologias e os grãos avariados (assim considerados os mofados, ardidos, quebrados, brotados, chochos e carunchados). Estudou-se também a variação na qualidade do milho ao longo do ano. Não houve diferenças significativas $(P>0,05)$ entre casas agropecuárias para os parâmetros de umidade, PB, grãos ardidos, mofados, carunchados, brotados e quebrados. Constatou-se que o teor de PB varia conforme a época, bem como o conteúdo de grãos avariados. Constatou-se vários valores abaixo do padrão mínimo de qualidade aceitável. Diferenças significativas $(P<0,05)$ foram detectadas entre as formas de determinação da umidade do milho, sugerindo necessidade de padronização da metodologia de avaliação.

Palavras Chave: Zea mays. Avariados. Controle de qualidade. Determinação da umidade.

\section{Introdução}

O Brasil se destaca mundialmente pela elevada produção de carnes, principalmente avícola. Dados do Sindirações (2011) mostram que a produção anual de rações em 2010 ultrapassou 61 milhões de toneladas, e o milho é o principal ingrediente. De acordo com a Associação Nacional Dos Fabricantes De Alimentos Para Animais (ANFAL, 2000), 65\% da produção nacional de milho é

\footnotetext{
1 Universidade Federal de Lavras, mestranda em nutrição e produção de ruminantes, Lavras, Minas Gerais (BR), davyany@yahoo. com.br (035) 92087282. Praça José Ferreira de Oliveira, 2, centro, Candeias - MG, CEP: 37280-000

2 Instituto Federal de Educação, Ciência e Tecnologia de Minas Gerais, campus Bambuí. Professor pesquisador. Bambuí, Minas Gerais (BR), luiz.machado@ifmg.edu.br (037) 34312046. Rua Joaquim Marciano de Faria, 77, Candola, Bambuí-MG, CEP: $38900-000$ 3 Instituto Federal de Educação, Ciência e Tecnologia Sudeste de Minas Gerais, campus Rio Pomba. Professor do departamento acadêmico de matemática, física e estatística, flavio.bittencourt@ifsudestemg.edu.br Rua Dr. José Sebastião da Paixão, s/n, Lindo Vale, Rio Pomba-MG, CEP: 36180-000

4 Universidade Federal de Minas Gerais, mestranda em nutrição animal, Belo Horizonte, Minas Gerais (BR), larissecristinapereira@ yahoo.com.br (037) 99681480. Rua Dez de Novembro, 254, Cerrado, Bambuí, MG CEP: 38900-000
} 
consumida na alimentação animal. Esse ingrediente é rico em amido de alta digestibilidade e fornece energia a um custo relativamente baixo.

Entretanto, os grãos de milho são passíveis de alterações físicas e químicas, o que acarreta diminuição de seu valor nutricional, pode prejudicar o desempenho animal e pode favorecer o aparecimento de substâncias tóxicas, como as micotoxinas (LOPES; FONTES; DONZELE, 1988; PIEDADE et al. 2002; RODRIGUES, 2009).

Rações com alta inclusão (20 a 40\%) de grãos contaminados por insetos e fungos e de grãos ardidos aumentam a incidência de alterações no fígado e no aparelho locomotor de frangos de corte (STRINGHINI et al.,2000). Provocam também queda na postura de ovos, sendo esta precedida pela redução de proteínas e lipídeos nos níveis sanguíneos (UTTPATEL et al., 2011). Em alevinos de jundiá, níveis crescentes de aflatoxinas na dieta causaram redução no crescimento e no ganho de peso (LOPES et al., 2009).

Os grãos de milho destinados ao consumo animal devem ter umidade adequada; estar isentos de fungos, micotoxinas, sementes tóxicas; e apresentar conteúdo tolerável de grãos ardidos, brotados, chochos, brotados, carunchados, quebrados e impurezas (BUTOLO, 2002). Ao analisar a distribuição das aflatoxinas nos grãos sabidamente contaminados, após uma segregação visual de defeitos, Piedade et al. (2002) verificaram que grãos não sadios apresentaram 84\% de contaminação.

A determinação do teor de umidade é de extrema importância para o controle de qualidade, pois umidade elevada (acima de 14\%) favorece o crescimento de fungos potencialmente produtores de micotoxinas (BIAGI; CARNEIRO; BERTOL, 2002). Existem diferentes maneiras para determinar a umidade, dentre as quais se destacam a utilização de estufas e o Determinador Universal de Umidade (DUU), um aparelho muito comum nas fábricas de rações. Contudo, não há pesquisas que comprovem a semelhança nos resultados entre esses métodos de determinação.

Produtores que trabalham em pequena escala carecem de meios e informações sobre a qualidade nutricional dos grãos e poucos trabalhos avaliam a qualidade desse importante ingrediente. 0 objetivo deste trabalho foi avaliar a qualidade do milho comercializado em casas agropecuárias ao longo de um ano e avaliar diferentes metodologias para determinar o teor de umidade.

\section{Material e métodos}

Este trabalho foi conduzido no Laboratório do Instituto Federal de Educação, Ciência e Tecnologia de Minas Gerais, campus Bambuí. O milho foi coletado em quatro casas agropecuárias em Bambuí-MG, entre março de 2009 e fevereiro de 2010.

As coletas foram realizadas no início de cada mês, por dois dias consecutivos, totalizando 2,0 kg por mês. Realizou-se nova amostragem através do sistema de quarteamento manual (Brasil, 2005). Parte da amostra resultante foi então moída em moinho analítico (peneira de $1,0 \mathrm{~mm}$ ) para a determinação do teor de umidade e proteína bruta, sendo para esse último utilizado o método Kjeidahl - conforme metodologia descrita no Compêndio (2005). Para as análises do teor de umidade dos grãos, foram avaliadas três metodologias:

a) Moídos: material moído e levado à estufa a $105^{\circ} \mathrm{C}$ por 4 horas;

b) Inteiros: grãos inteiros levados à estufa a $100^{\circ} \mathrm{C}$ por 24 horas;

c) DUU: grãos inteiros levados ao Determinador de Umidade Universal (DUU), modelo BURROWS WWC, utilizando as metodologias de Silva e Queiroz (2002).

Para avaliar o teor de grãos avariados, 100 g deste material foi utilizado, sendo as impurezas (sabugo, sementes, palha, etc.) e grãos quebrados separados (crivo de $5 \mathrm{~mm}$ ). Os grãos restantes 
foram classificados em brotados, ardidos, chochos, mofados e carunchados, conforme a metodologia de Butolo (2002), sendo determinada a quantia de cada categoria.

Para estudar a umidade, adotou-se cada estabelecimento como controle local (bloco) e as repetições corresponderam aos meses em que foram coletadas as amostras. Dessa forma, as três metodologias foram comparadas.

Os dados foram submetidos à analise de variância (ANOVA) e a comparação das médias foi realizada pelo teste de Tukey (5\%), utilizando o software de análise estatística SISVAR (Ferreira, 2000).

\section{Resultados e discussão}

Para o teor de umidade, não foram encontradas diferenças significativas entre os estabelecimentos, provavelmente por serem os grãos de mesma origem. A Tabela 1 mostra que há diferenças significativas $(p<0,05)$ entre as metodologias adotadas para a aferição da umidade dos grãos. 0 DUU proporcionou os valores mais elevados, seguido do método que avalia o grão triturado. 0 método oficial, proposto pelo Compêndio (2005), baseia-se em deixar a amostra moída em estufa a $105^{\circ} \mathrm{C}$ durante 4 horas. Embora a metodologia do DUU tenha apresentado resultados mais elevados, ela é mais utilizada nas fábricas de rações, pois disponibiliza resultados em curto intervalo de tempo em comparação com as outras metodologias.

Tabela 1. Médias para os teores de umidade no milho nas diferentes metodologias. Bambuí, 2010.

\begin{tabular}{cc}
\hline Metodologia & Umidade (\%) \\
\hline Grão & $12.96 \mathrm{c}$ \\
Triturado & $13.56 \mathrm{~b}$ \\
DUU & $14.33 \mathrm{a}$ \\
\hline CV (\%) & 10,20
\end{tabular}

Médias seguidas de letras diferentes diferem entre si pelo teste Tukey ao nível de 5\% de probabilidade.

Fonte: Elaboração própria.

O comportamento do teor de umidade ao longo dos meses, em função das diferentes metodologias de medida, está na Figura 1. A elevação na umidade dos grãos corresponde ao período de maio a junho, meses onde há colheita e armazenamento dos grãos, e nos meses subsequentes o teor de umidade decresce. Faroni et al. (2005) observou decréscimo na umidade dos grãos de milho ao longo de 180 dias de armazenamento, com o teor de água dos grãos variando de $13,5 \% \mathrm{com} 25^{\circ} \mathrm{C}$ no início o experimento, a 12,5 e 10,5\% para as temperaturas de 30 e $40^{\circ} \mathrm{C}$, respectivamente. 
Figura 1. Variação da umidade de grãos de milho de março de 2009 a fevereiro de 2010, de acordo com diferentes metodologias de determinação. Bambuí, 2010.

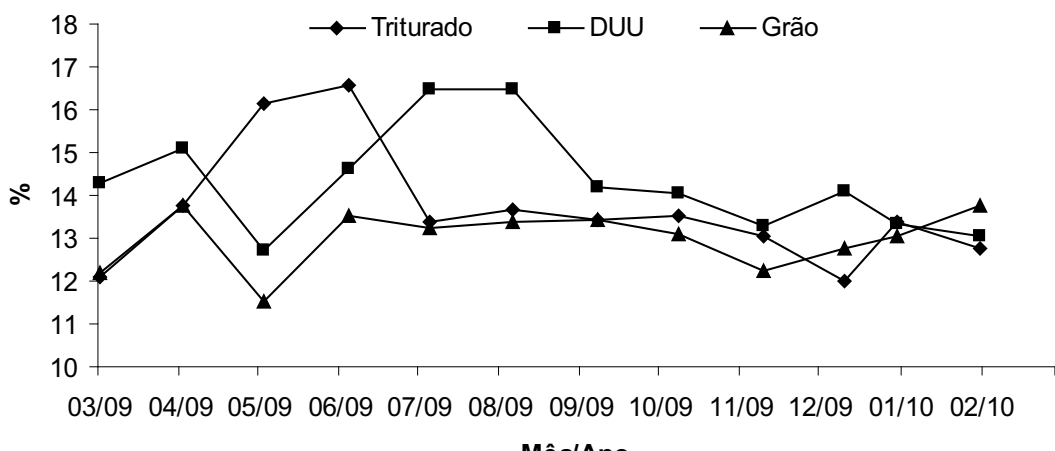

Mês/Ano

Fonte: Elaboração própria.

Rostagno (2005) propõe o valor de $12,89 \%$ para a umidade do milho, sendo esse semelhante aos valores observados para as determinações que utilizaram estufa neste trabalho. O Compêndio (2005) propõe 13,0\% como nível máximo para a umidade do milho; por outro lado, a Portaria do Ministério da Agricultura $n^{\circ} 845$, de 8 de novembro de 1976, que propõe a classificação nacional do milho, determina a umidade máxima permitida em 14,5\%. Durante o período avaliado, algumas amostras extrapolaram o limite máximo tolerável (Figura 1). A umidade do milho é um parâmetro de extrema importância na recepção de grãos e pode variar conforme muitos fatores relacionados ao meio. Lima (2010) cita que foram verificados teores de umidade variando de 8,03 a $17,31 \%$ em diferentes partidas.

Quanto ao conteúdo de grãos avariados, não houve diferenças significativas entre os diferentes estabelecimentos para nenhum dos parâmetros avaliados $(P>0,05)$. Entretanto, alguns apresentaram valores preocupantes em determinados meses do ano (Tabela 2 ).

Rostagno (2005) propõe uma equação de predição que relaciona a diminuição do valor de energia metabolizável do milho com a presença de grãos avariados, podendo ser adotada no momento da formulação. Silva, Couto e Ferreira (2008) avaliaram o milho com diferentes densidades obtido a partir de variações na composição dos avariados, e perceberam grande redução nos valores de energia metabolizável para aves de corte, com milho de menores densidades. Essa diferença não é considerada por muitos produtores que compram milho em pequenos estabelecimentos agropecuários.

Tabela 2. Porcentagem de grãos avariados das amostras obtidas nas casas agropecuárias da cidade de Bambuí, março/2009 a fevereiro/2010. Bambuí, 2010.

\begin{tabular}{cccccccccccccc}
\hline \multirow{2}{*}{ Categoria } & \multicolumn{10}{c}{ Mês/Ano } \\
\cline { 2 - 15 } & $\mathbf{0 3 / 0 9}$ & $\mathbf{0 4 / 0 9}$ & $\mathbf{0 5 / 0 9}$ & $\mathbf{0 6 / 0 9}$ & $\mathbf{0 7 / 0 9}$ & $\mathbf{0 8 / 0 9}$ & $\mathbf{0 9 / 0 9}$ & $\mathbf{1 0 / 0 9}$ & $\mathbf{1 1 / 0 9}$ & $\mathbf{1 2 / 0 9}$ & $\mathbf{0 1 / 1 0}$ & $\mathbf{0 2 / 1 0}$ \\
\hline Carunchados & - & - & 0,07 & 0,25 & 0,35 & 1,63 & 7,13 & 20,00 & - & - & 0,45 & 0,20 \\
Ardidos & 3,75 & 2,79 & 1,92 & 1,01 & 1,93 & 1,68 & 1,34 & 1,59 & 1,07 & 1,94 & 2,29 & 1,03 \\
Quebrados & 5,00 & 3,93 & 5,23 & 8,12 & 7,56 & 5,50 & 8,06 & 8,91 & 7,93 & 6,15 & 5,10 & 10,12 \\
Mofados & - & 0,13 & - & - & - & - & - & - & - & - & - & - \\
$\begin{array}{c}\text { Brotados } \\
\text { Chochos }\end{array}$ & 0,75 & 0,31 & 0,05 & - & 0,31 & 0,27 & - & 0,30 & - & - & - & 0,14 \\
\hline $\begin{array}{c}\text { Avariados } \\
\text { totais }\end{array}$ & 10,25 & 7,86 & 7,60 & 9,38 & 10,42 & 9,55 & 16,53 & 30,80 & 9,00 & 8,09 & 7,83 & 11,49 \\
\hline
\end{tabular}

Fonte: Elaboração própria. 
Para grãos quebrados, o maior valor encontrado foi de 10,12\% (Figura 2), o que se enquadra no limite máximo para grãos quebrados descrito no Compêndio (Brasil, 2005), mas extrapola o desejável, que seria de 7\%. 0 excesso de grãos quebrados favorece o desenvolvimento de fungos produtores de micotoxinas. Nos animais, as micotoxinas são absorvidas rapidamente pelo intestino, sendo os monogástricos mais sensíveis à contaminação do que os ruminantes possuidores de processos de desintoxicação no rúmen (BERSJØ et al., 1992; BERSJØ et al. 1993; FRIEND et al., 1992). Nas aves, uma vez absorvida, as aflatoxinas ligadas e não ligadas a proteínas séricas espalham-se pelos tecidos, especialmente o fígado. No fígado, as aflatoxinas são biotransformadas pelo sistema microssomal hepático em metabólitos muito tóxicos, provocando alteração nas propriedades funcionais do órgão e na síntese das proteínas (TESSARI et al., 2006).

Para grãos ardidos, a maior porcentagem encontrada foi de 3,75\%, (Figura 2), sendo a máxima permitida pela legislação de 3\%, embora o desejável seja 1\%. Estes grãos conferem baixa palatabilidade às rações e reduzem seu consumo pelos animais, o que contribui para depreciar o produto $e$ diminuir o seu valor nutritivo (Ribeiro et al., 2005). A ocorrência desses grãos no milho é o reflexo de fungos presentes no campo e após colheita. Leal (2012) mostrou que, a cada 1\% de inclusão de grãos de milho ardidos nas rações oferecidas a aves de corte com idade entre 1 e 21 dias, houve depreciação nos valores de matéria seca, fibra bruta, extrato etéreo e energia bruta em 0,011\%, 0,008\%, 0,017\% e 2,55 Kcal respectivamente. No desempenho, essas perdas refletiram em diminuição de 0,65 g no ganho de peso das aves, e uma piora de 0,001 g/g na conversão alimentar.

Figura 2. Percentual de grãos ardidos e quebrados no período de março de 2009 a fevereiro de 2010. Bambuí, 2010.

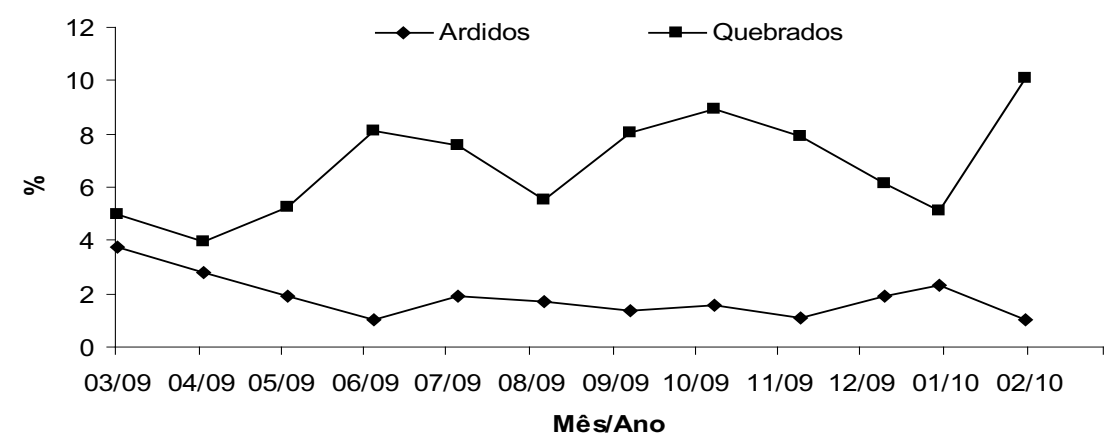

Fonte: Elaboração própria.

Quanto à presença de grãos chochos, foram observados valores elevados nos meses de março, abril e agosto de 2009. Os grãos chochos são desprovidos de massa interna, ou seja, têm menor conteúdo quando comparados aos grãos normais.

Nos meses de março, abril, julho e outubro foram observados valores superiores a $0,30 \%$ de grãos brotados. Esse valor é considerado alto, pois muitas fábricas de ração rejeitam cargas quando detectam a presença de grãos brotados.

Somente foram observados grãos mofados em abril, mas numa quantidade superior a $1 \%$, o que é inadmissível para um lote de milho.

Grãos avariados tiveram maior incidência nos meses de colheita e armazenamento do milho, já que as avarias ligam-se à alta umidade do grão (Figura 3 ). 
Figura 3. Percentual de grãos mofados, brotados e chochos no período de março/2009 a feverei$\mathrm{ro} / 2010$.

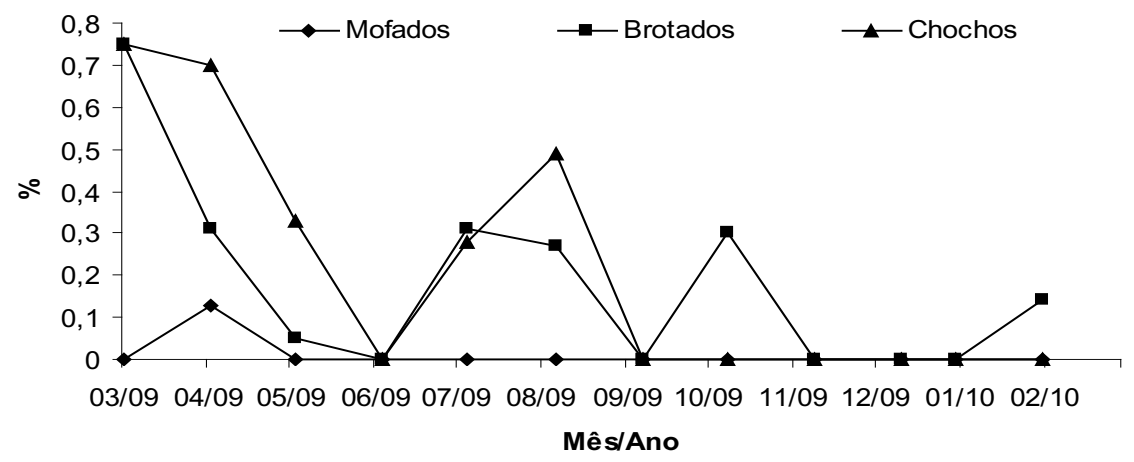

Fonte: Elaboração própria.

A quantidade de grãos carunchados encontrada nos meses de setembro e outubro foi extremamente elevada. Nesses meses, há aumento significativo da temperatura e da umidade ambiental, que contribuem para o ataque de insetos. A situação se normalizou em novembro em função do tratamento do milho por processo de expurgo.

Deve-se enfatizar que o máximo permitido para grãos carunchados é de 1,0\%. 0 ataque por caruncho reduz o valor nutricional do grão e também favorece fungos produtores de micotoxinas (BUTOLO, 2002). Lopes, Fontes e Donzele (1988) submeteram grãos de milho a diferentes níveis de carunchamento e concluíram que os grãos perderam $10,0 \%$ do peso e que o nível de energia metabolizável decresceu ligeiramente. O nível de avariados total se manteve próximo a 10,0\% durante o ano, com níveis críticos em setembro e outubro (Figura 4), sendo essa elevação provocada principalmente por altos conteúdos de grãos carunchados nesses meses.

Figura 4. Percentual de grãos carunchados e avariados total no período de março/2009 a fevereiro/2010. Bambuí, 2010.

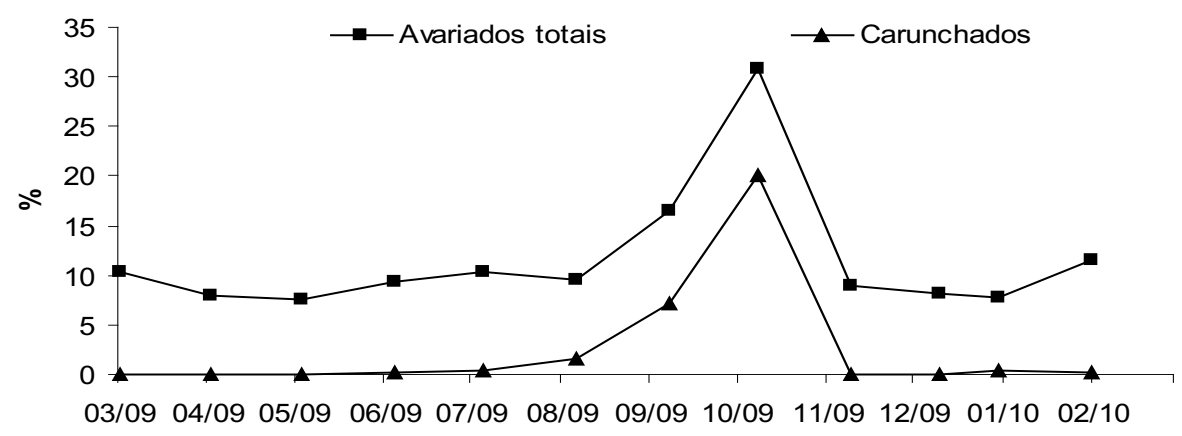

Mês/Ano

Fonte: Elaboração própria.

Considerando a Resolução CONCEX n 103, de 21 de outubro de 1975 e a Portaria do Ministério da Agricultura $n^{\circ} 845$, de 8 de novembro de 1976, o milho analisado se enquadra na classificação "Tipo 1", mas extrapola os limites dessa classificação em alguns meses, principalmente setembro e outubro. 
Não houve diferença significativa para o nível de proteína bruta dos grãos coletados em diferentes estabelecimentos. Na comparação entre os meses, foi observada diferença significativa $(P<0,05)$ entre os meses de junho e julho, provavelmente provocada pela substituição do milho estocado pelo recém colhido.

Tabela 3. Valores de proteína bruta (PB), em porcentagem, do milho comercializado a varejo de março de 2009 a fevereiro de 2010. Bambuí, 2010.

\begin{tabular}{cc}
\hline Mês/Ano & PB(\%)* \\
\hline $03 / 09$ & $7,46 \mathrm{ab}$ \\
$04 / 09$ & $6,90 \mathrm{ab}$ \\
$05 / 09$ & $7,55 \mathrm{ab}$ \\
$06 / 09$ & $6,40 \mathrm{~b}$ \\
$07 / 09$ & $8,26 \mathrm{a}$ \\
$08 / 09$ & $7,12 \mathrm{ab}$ \\
$09 / 09$ & $7,69 \mathrm{ab}$ \\
$10 / 09$ & $7,11 \mathrm{ab}$ \\
$11 / 09$ & $7,03 \mathrm{ab}$ \\
$12 / 09$ & $7,53 \mathrm{ab}$ \\
$01 / 10$ & $7,36 \mathrm{ab}$ \\
$02 / 10$ & $7,34 \mathrm{ab}$ \\
\hline
\end{tabular}

${ }^{*} \mathrm{CV}=9,31 \%$. Média Geral $=7,31 \%$

Médias com letras diferentes na mesma linha diferem entre si pelo teste Tukey ao nível de 5\% de significância.

Fonte: Elaboração própria.

Os valores da proteína bruta oscilaram ao longo do ano de 6,40\% a 8,26\%. 0 valor citado pelo Compendio (2005) é de 7,5\%. Lima (2010) cita que o teor de proteína bruta do milho está relacionado com o nível de nitrogênio do solo e que, em níveis elevados, há acúmulo de nitrogênio não proteico pela planta.

Caso se formulem rações considerando o valor proposto por Rostagno (2005), utilizando o material comercializado, haverá um déficit de proteína que poderá proporcionar queda no desempenho animal. Portanto, os formuladores devem corrigir a proteína bruta em suas matrizes sempre que trabalharem com lotes diferentes de milho.

Rodrigues et al. (2003), ao testar vários tipos de milhos com diferentes procedências (variedades ou regiões) para frangos de corte, encontraram diferenças no desempenho, na digestibilidade dos nutrientes e nos valores energéticos das rações.

Os testes de umidade que utilizam o determinador universal de umidade e grãos inteiros proporcionam estimativas superiores da umidade real do milho. 0 nível de umidade máximo foi ultrapassado em alguns meses do ano.

Em alguns meses, os níveis de grãos avariados foram superiores aos propostos pela legislação, o que pode proporcionar prejuízos aos produtores que utilizam esse material. É necessário maior rigor na fiscalização do milho. 
Figura 5. Flutuação do teor de proteína bruta (PB) do milho comercializado a varejo ao longo de um ano. Bambuí, 2010.

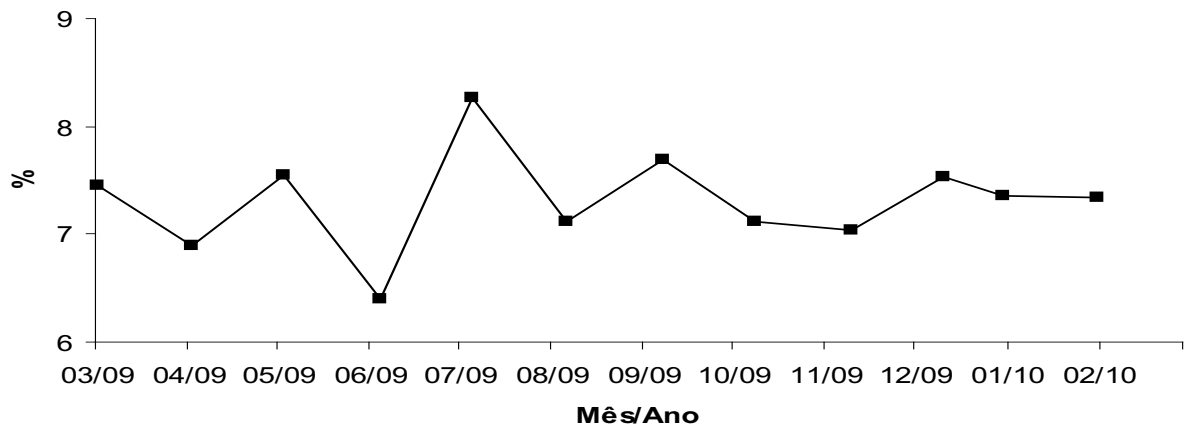

Fonte: Elaboração própria.

\section{Conclusões}

Entre as casas agropecuárias, não houve diferença para os parâmetros de umidade, proteína bruta, grãos ardidos, mofados, carunchados, brotados e quebrados. 0 teor de proteína bruta varia conforme a época, bem como o conteúdo de grãos avariados. Houve diferenças entre as formas de determinação da umidade do milho, sugerindo necessidade de padronização da metodologia para avaliação.

Os teores de grãos mofados e carunchados extrapolaram limites máximos aceitáveis e os quebrados e ardidos não atenderam o desejável. Recomendam-se a fiscalização mais rigorosa do milho destinado aos animais e a realização de trabalhos que possam inferir os parâmetros de composição centesimal do milho a fim de avaliar a sua qualidade para a nutrição animal.

\section{Quality of retailed maize for animal feed and methods for determining mois- ture}

\section{Abstract}

Brazil has reached the milestone of 61 million tons of feed produced, and approximately $65 \%$ of this amount is comprised of corn, whose nutritional quality is influenced by several factors. Part of the commercialized maize does not go through quality control and is accepted without any restrictions. The aim of this study was to evaluate the quality of the corn sold at retail and determine its moisture by different methods, since several methods can be used without the certainty of their reliability. Corn samples were collected from four agricultural stores in Bambuí-MG for 12 months. It was evaluated the crude protein (CP), moisture in three different methodologies and damaged grains (thus considered the musty, burnt, broken, sprouted, hollow and rotten). The variation in the quality of the maize throughout the year was also studied. It was found no significant differences $(P>0.05)$ between agricultural stores for the parameters of moisture, crude protein, fermented, moldy, rotten, sprouted and broken. It was found that the CP content varies according to the season as well as the contents of damaged grains. Multiple values below the minimum standard of acceptable quality were found. Significant differences $(P<0.05)$ were found between the means for determining the moisture corn, suggesting the need for standardization of evaluation methodology.

Keywords: Zea mays. Damaged. Quality Control. Determination of moisture. 


\section{Referências bibliográficas}

ANFAL (ASSOCIAÇÃO NACIONAL DOS FABRICANTES DE ALIMENTOS PARA ANIMAIS). Perfil 2000: Indústria brasileira de alimentação animal. Alimentação Animal, São Paulo, v.5, n.17, 2000. (Encarte)

BERSJØ, B., MATRE, T., NAFSTAD, I. Effect of diets with graded levels of deoxynivalenol on performance in growing pigs. Journal of Veterinary Medicine. v. 39, n. 1-10, p. 752-758, fev./dez. 1992.

BERSJ $\emptyset$, B. et al. The effects of naturally deoxynivalenol-contaminated oats on the clinical contation, blood parameters, performance and carcass composition of growing pigs. Veterinary Research Communications, v. 17, n. 4, p. 283-294, jul. 1993. Disponível em: <http://link. springer.com/content/pdf/10.1007\%2FBF01839219.pdf>. Acesso em: 15 mai. 2013.

BIAGI, J. D.; CARNEIRO, M. C.; BERTOL, R. Armazenamento de cereais. In: SIMPÓSIO SOBRE INGREDIENTES NA ALIMENTAÇÃO ANIMAL, 2., 2002, Uberlândia. Anais... Campinas: CBNA, 2002. p. 117-133.

BUTOLO, J. E. Qualidade de ingredientes na alimentação animal. Campinas: Colégio Brasileiro de Nutrição Animal, 2002.

BRASIL. Portaria n 845, de 8 de novembro de 1976. Diário Oficial da União, Brasília, DF, 19 nov. 1976. Seção1, p. 1787. Disponível em:<http://extranet.agricultura.gov.br/sislegisconsulta/ consultarLegislacao.do?operacao=visualizar\&id=1133>. Acesso em: 02 jan. 2012.

BRASIL. Ministério da Agricultura, Pecuária e Abastecimento. Compêndio Brasileiro de Alimentação Animal. Brasília, 2005.

FARONI, L. R. D'A. et al. Avaliação Qualitativa e quantitativa do milho em diferentes condições de armazenamento. Engenharia na Agricultura, v. 13, n. 3, 2005, p.193-201. Disponível em: <http://www.ufv.br/dea/reveng/arquivos/Vol13/v13n3p193-201.pdf>. Acesso em: 15 mai. 2013.

FERREIRA, D. F. Manual do sistema Sisvar para análises estatísticas. Lavras: Universidade Federal de Lavras, 2000.

FRIEND, D.W., THOMPSON, B.K., TRENHOLM, H.L. et al. Toxicity of T-2 toxin and its interaction with deoxynivalenol when fed to young pigs. Canadian Journal of Animal Science, v. 72, n. 3, p. 703-711, set. 1992. Disponível em: <http://pubs.aic.ca/doi/pdf/10.4141/cjas92-082 >. Acesso em: 15 mai. 2013.

LIMA, G. J. M. M. de. Milho: o grão que vale ouro nas dietas de aves... mas que ainda não recebeu a devida importância do setor produtivo. Produção Animal Avicultura: a revista do AviSite, ano 4, n. 39, p. 48-52, jul. 2010. Disponível em: <http://www.avisite.com.br/revista/pdfs/revista edicao39.pdf>. Acesso em: 15 mai. 2013.

LEAL, P. C. Qualidade de grãos de milho em dietas para frangos. 2012. 99 p. Dissertação (Mestrado). Universidade Federal do Paraná, Curitiba. 
LOPES, D. C.; FONTES, R. A.; DONZELE, J. L. Perda de peso e mudanças na composição química do milho (Zea mays) devido ao carunchamento. Revista Brasileira de Zootecnia, v. 17, n. 4, 1988, p. 367-371.

LOPES, P. R. S. et al. Utilização de absorvente em rações contendo aflatoxinas para alevinos de jundiá. Revista Brasileira de Zootecnia, v. 38, n. 4, 2009, p. 589-595.

PIEDADE, F. S. et al. Distribution of aflatoxins in corn fractions visually segregated for defects. Brazilian Journal of Microbiology, v. 33, n. 3, p. 250-254, set. 2002. Disponível em: <http:// www.scielo.br/pdf/bjm/v33n3/v33n3a13.pdf>. Acesso em: 15 mai. 2013.

RIBEIRO, N.A. et al. Incidência de podridões do colmo, grãos ardidos e produtividade de grãos de genótipos de milho em diferentes sistemas de manejo. Ciência Rural, v. 35, n. 5, p.1003-1009, 2005.

RODRIGUES, P. B. et al. Desempenho de frangos de corte, digestibilidade de nutrientes e valores energéticos de rações formuladas com vários milhos, suplementados com enzimas. Revista Brasileira de Zootecnia, v.32, n.1, 2003, p. 171-182.

RODRIGUES, S. I. F.C. Avaliação da qualidade do milho e predição da energia metabolizável para uso em avicultura. 2009. 106 p. Tese (Doutorado). Universidade de Brasília, Brasilia.

ROSTAGNO, H. S. Tabelas brasileiras para aves e suínos: composição de alimentos e exigências nutricionais. 2 ed. Viçosa: Editora UFV, 2005. 186 p.

SILVA C. S.; COUTO H. P.; FERREIRA R. A. Valores nutricionais de milhos de diferentes qualidades para frangos de corte. Revista Brasileira de Zootecnia, v. 37, n. 5, 2008, p. 883-889.

SILVA, D.J.; QUEIROZ, A.C. Analise de alimentos: métodos químicos e biológicos. 3 ed. Viçosa: Editora UFV, 2002.

SINDIRAÇÕES. Boletim Informativo do Setor. Março 2011. Setor de Alimentação Animal. 2011. 5 p.

STRINGHINI, J. H. et al. Efeito da qualidade do milho no desempenho de frangos de corte. Revista Brasileira de Zootecnia, v. 29, n. 1, 2000, p. 191-198.

TESSARI, E.N.C. et al. Effects of aflatoxin B1 and fumonisin B1 on body weight, and histology of broiler chicks. British Poultry Science, v. 47, n. 3, p. 357-364, jun. 2006.

UTTPATEL, R. et al. Desempenho produtivo de matrizes de corte submetidas a dietas contendo aflatoxinas e gluconanos esterificados como adsorventes. Revista Brasileira de Zootecnia, v. 40, n. 4, 2011, p. 821-826.

\section{Histórico editorial}

Recebido: 17/09/2012

Avaliação e copidesque: 21/09/2012 a 20/06/2013 